\title{
RETROSPECTIVE ANALYSIS OF THORACIC TRAUMA AND EVALUATION OF THE FACTORS AFFECTING THE DURATION OF STAY IN THE HOSPITAL
}

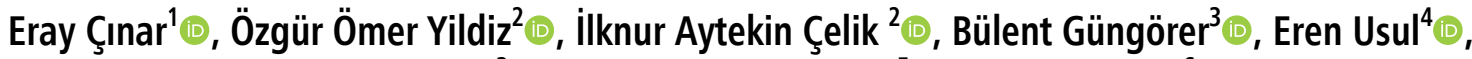 \\ Şükrü Yorulmaz ${ }^{3} \odot$, Eylem Kuday Kaykısız ${ }^{5} \odot$, Kamil Safiejko ${ }^{6} \odot$ \\ ${ }^{1}$ Department of Thoracic Surgery, Ankara City Hospital, Turkey \\ ${ }^{2}$ Department of Thoracic Surgery, Yıldırım Beyazıd University Faculty of Medicine, Ankara, Turkey \\ ${ }^{3}$ Department of Emergency Medicine, Ankara City Hospital, Turkey \\ ${ }^{4}$ Department of Emergency Medicine, Sincan Dr. Nafiz Körez State Hospital, Ankara, Turkey \\ ${ }^{5}$ Department of Emergency Medicine, Denizli State Hospital, Turkey \\ ${ }^{6}$ Department of General and Endrocrinological Surgery, Medical University of Bialystok, Poland
}

\section{ABSTRACT}

INTRODUCTION: The aim of this study is to evaluate the epidemiological and demographic features, treatment types of patients with thoracic trauma, as well as the duration of hospital stay and the factors affecting mortality.

MATERIAL AND METHODS: This retrospective cross-sectional study included patients who applied to the emergency room in a tertiary care hospital, between 2017-2019 and having thoracic trauma. Patients; age, gender, date of application, type of injury (blunt or penetran), arrival saturation, use of anticoagulants, type of injury, side of injury (right, left, bilateral) additional injury, hospitalization and mortality status were recorded. $\mathrm{P}<0.05$ was considered as statistically significant.

RESULTS: Total of 113 people were included in the study. The average age was $52.15 \pm 20.3$. The most common reason of applying to the hospital was falling with 50 patients. A negative weak correlation was found between saturation and age and hospital stay. In terms of pathology and gender, there was no statistically significant difference in mortality.

CONCLUSION: As a result, in this study, thoracic trauma occurs mostly in men and due to falls and motor vehicle accidents, and the majority of injuries due to thoracic trauma can heal without follow- up or tube thoracostomy.

KEY WORDS: thoracic trauma, duration of hospital stay, mortality

Disaster Emerg Med J 2020; 5(3): 159-163

\section{INTRODUCTION}

Trauma has been and continues to be an important health problem both in Turkey and in the world. $10-15 \%$ of the patients exposed to trauma have life-threatening injuries [1]. And the thorax traumas are the most often ones after abdominal and head traumas. They are indicated as the reason for death $[2,3]$. In both blunt and penetran thoracic injuries, serious injuries can be observed such as rib fracture, pneumothorax, hemothorax, contusion, tracheal or bronchial injuries, major artery injuries and air embolism [3]. Blunt thorax 
traumas generally occur together with other system injuries.

There is no consensus in the approach to thorax trauma in the clinic of trauma patients, due to differences in mortality and morbidity rates in a wide range of studies, which may vary depending on the occurrence of the event, and isolated thoracic trauma, especially in blunt trauma patients.

The aim of this study is to evaluate the epidemiological and demographic features, treatment types of patients with thoracic trauma, as well as the duration of hospital stay and the factors affecting mortality.

\section{MATERIAL AND METHODS}

This retrospective cross-sectional study included patients who applied to the emergency room in Ataturk Education and Research Hospital, a third level public hospital between the dates of 2017 and 2019 and having thoracic trauma.

Prior to the study, the Ankara City Hospital ethics committee approved the study (with a number of E1-20-363 and a date of 27.02.2020). The data were obtained by scanning the hospital data system and patient files after obtaining permission from the hospital management.

Patients who were admitted to the emergency department with thoracic trauma or multi- trauma between the dates of 01.01.2017-01.01.2019 were included in the study. Patients with ongoing forensic investigations, with missing data in the file, referred to another center, or leaving the hospital refusing treatment, who had been ex following the resuscitation in the emergency service, and absolute fatal trauma were excluded from the study. A total of 113 patients were included in the study since of 146 patients who met the criteria, 14 were under on-going forensic investigations, 7 were ex in the emergency room and 12 were sent to another center or they went to their request and were excluded from the study. Patient's age, gender, date of application, type of injury (blunt or penetran), arrival saturation, use of anticoagulants, type of injury, side of injury (right, left, bilateral) additional injury, hospitalization and mortality status were recorded.

\section{STATISTICAL ANALYSIS}

Data were evaluated using Statistical Package for the Social Sciences 23.0 (SPSS), IBM, USA. Data are presented in mean \pm Standard Deviation (SD) or $\mathrm{n}(\%)$, where appropriate. Comparison of the categorical data between groups was used chi-square test. Analysis of variance (ANOVA) was used for comparing normally distributed continuous data of more than two groups. Correlations between continuous variables were tested using Spearman's rho. $\mathrm{P}<0.05$ was considered as statistically significant.

\section{RESULTS}

Total of 113 people were included in the study. The average age was $52.15 \pm 20.3 .29(25.7 \%)$ of the patients included in the study were women and $84(74.3 \%)$ of them were men. The most common reason of applying to the hospital was falling with 50 patients. It was followed by motor vehicles accidents $(n=47) .4$ patients applied to the hospital due to pounding; 1 patient applied due to firearm injuries and 11 patients applied to the hospital sue to various reasons such as occupational accidents, being kicked by an animal.

$55(48.7 \%)$ patients had the injuries on the left side, while $45(39.8 \%)$ had it on the left and 6 (5.3\%) had bilaterally. Pathologically, 15 (13.3\%) patients had hemothorax, 17 (15.0\%) had pneumothorax, 7 (6.2\%) haemopneumothorax, 79 (69.9\%) rib fracture and 22 (19.5\%) contusion. Injury-wise, 105 (92.9\%) were impacted by obtuse injury, 4 (3.5\%) penetran injury, 4 (3.5\%) had a spontaneous pneumothorax. There was anticoagulant use in 23 patients (20.4\%).

While 51 of the patients (45.1\%) are monitored without a procedure, $62(54.9 \%)$ of the patients received the surgical procedure. Oxygen saturations of the patients monitored without procedure were statistically significantly higher than those of patients who underwent surgery $(p=0.007)$. There was no statistically significant difference between the groups in terms of age $(p=0.115)$ (Tab. 1).

When the duration of hospital stay was analyzed, there were 100 patients hospitalized. 72 of them were male and 28 were female. Duration of hospital stay ranged from 1-15 days.

While there was no gender difference in terms of hospitalization, there was a statistically significant difference between the groups according to the existing pathology $(p<0.001)$ (Tab. 2). When the correlation of the duration of the hospital stay with age and oxygen saturation was analyzed, a negative weak correlation was found between saturation 
Table 1. Effect of age and oxygen saturation level on hospital stay

\begin{tabular}{|l|l|c|c|c|c|}
\hline \multicolumn{2}{|c|}{} & Age & SO2 & Stay & \\
\hline \multirow{2}{*}{ Age } & Pearson Correlation & 1 & $-0.210^{*}$ & 0.180 & \\
\cline { 2 - 6 } & Sig. (2-tailed) & & 0.028 & 0.073 & $-0.366^{* *} 1--0.21^{0 *}$ Pearson CorrelationSO2100110113N \\
\cline { 2 - 6 } & Sig. (2-tailed) & 0.028 & & 0.000 & \\
\cline { 2 - 6 } & N & 110 & 110 & 100 & \\
\cline { 2 - 6 } & Pearson Correlation & 0.180 & $-0.366^{* *}$ & 1 & $100100100 \mathrm{~N} .000 .073$ Sig. (2-tailed) \\
\hline
\end{tabular}

${ }^{*}$ Correlation is significant at the 0.05 level (2-tailed). ${ }^{* *}$ Correlation is significant at the 0.01 level (2-tailed)

\begin{tabular}{|c|c|c|}
\hline Pathology & $\begin{array}{c}\text { Min-max } \\
\text { (day) }\end{array}$ & Mean \pm SD \\
\hline Pneumothorax & $1-9$ & $4.63 \pm 2.11$ \\
\hline Hemothorax & $2-10$ & $5 \pm 2.569$ \\
\hline Hemopneumotorax & $3-9$ & $5.28 \pm 2.058$ \\
\hline Contusion & $1-15$ & $3.47 \pm 3.059$ \\
\hline $\begin{array}{l}\text { Other pathologies (Costa } \\
\text { fracture etc.) }\end{array}$ & $0-8$ & $2.22 \pm 1.776$ \\
\hline
\end{tabular}

SD - Standard Deviation

and age and hospital stay $(r=-0.210, p=0.028$; $r=-0.366, p<0.001$ respectively) (Tab. 3).

Considering the prognosis of the patients, $6(5.3 \%)$ died. One of the patients was female and there was no statistically significant difference in mortality in terms of gender ( $p=0.515)$. Regarding the existing pathologies of patients who died, hemopneumothorax was found in 1 patient and pneumothorax in 3 patients. In terms of pathology, there was no statistically significant difference in mortality ( $p=0.133)$. There was anticoagulant use in only 1 of the patients who died, which was statistically insignificant $(p=0.646)$.

\section{DISCUSSION}

In this study, in which thorax traumas were included, the most common reason for hospital application was fall and motor vehicle accidents which is consistent with the literature. Blunt thoracic traumas generally occur due to motor vehicle accidents, falls, pounding and accidents caused by animals [4]. Both blunt and penetrant thoracic traumas are more common in the male gender in the literature, as the reason for this is shown to be the number of men working in dangerous jobs as well as the excess of male sex in traffic $[5,6]$. In this study, $74.3 \%$ of the patients were male, consistent with the literature.
Table 3. Comparison of pathology groups by the length of hospital stay

\begin{tabular}{|l|c|c|c|c|c|}
\hline & $\begin{array}{c}\text { Sum of } \\
\text { Squares }\end{array}$ & df & $\begin{array}{c}\text { Mean } \\
\text { Square }\end{array}$ & $F$ & Sig. \\
\hline Between Groups & 137.918 & 4 & 34.479 & 6.856 & 0.000 \\
\hline Within Groups & 477.792 & 95 & 5.029 & & \\
\hline Total & 615.710 & 99 & & & \\
\hline
\end{tabular}

Rib fracture is seen in $35-50 \%$ of the patients exposed to thoracic trauma [7-9]. Isolated rib fractures should be followed conservatively [10]. At this stage, atelectasis is the major component of pain control to prevent blood gas abnormalities and hypoventilation-related pneumonia [9]. In addition, it should be kept in mind that additional complications such as contusion, pneumothorax or hemothorax may develop if the patient becomes worse during monitoring, and the patient should be evaluated again [11]. In this study, the rate of rib fracture is high (69.9\%) compared to the literature. However, in a study by Segen et al, rib fracture was reported to be $71 \%$, which is consistent with this study [12]. This may be due to the inclusion of not only the patients with rib fractures but also with additional complications to rib fracture such as hemothorax and pneumothorax.

The fractures in the sternum and the first 3 clavicles should be stimulating due to high-energy trauma. $8 \%$ of all blunt thoracic traumas are seen in the sternum fracture, and sternum fractures are managed conservatively with pain control, such as elevation fractures [13]. Rarely, surgery may be considered in the presence of lung herniation, anterior chest wall defect, or non-boiling sternum for more than 6 weeks [14]. The clinician should be in alert in the presence of a sternum fracture is whether there is a cardiac injury. Because the cardiac injury is reported in $18-64 \%$ of sternum fractures [15]. EKG and troponin should be followed. Patients who do not have any sign of cardiac injury can be monitored in the service 
and no intensive care monitoring is required. In this study, 5 patients ( $4.3 \%$ ) had sternum fractures, and all patients were monitored with analgesics and no surgical treatment was performed. However, no heart injury was found in any patient in this study.

Similarly, scapula fractures are indicative of high energy trauma. In a study by Thompson et al., scapula fractures were reported to be observed together with $53.6 \%$ rib fracture, $53.6 \%$ pulmonary contusion, $26.8 \%$ clavicle fracture, $12.5 \%$ brachial plexus injury and $10.7 \%$ subclavian, brachial or axillary artery injuries [16]. In this study, 2 patients had scapula fracture and thoracotomy was performed in both patients. There was no major vascular injury in this study. In some other studies conducted in Turkey, no major vascular injuries were reported $[17,18]$. This may be due to the absolute mortality of major vascular injuries due to thoracic trauma and the loss of life at the scene before coming to the emergency room.

Pneumothorax, hemothorax and hemopneumothorax are among the most common injuries in thorax trauma $[5,6]$. In Turkey, the incidence of pneumothorax is reported as $\% 25$, hemopneumothorax as \%16-20 and haemothorax as approximately \%20 [19]. In 2007, Altunkaya et. al. reported the rate of pneumothorax as $33 \%$. In this study, the rate of pneumothorax was $15 \%$, hemothorax $13.3 \%$ and hemopneumothorax $6.2 \%$. These rates, which are lower than the literature, may be due to the exclusion of the patients with absolute fatal additional system injuries, patients who died either in the emergency service or at the scene, where thoracic trauma was not at the forefront.

These rates, which are lower than the literature, may be due to the inclusion of patients with an absolute fatal additional system injury, in which the thoracic trauma was not in the foreground, who died in the emergency service or on the scene. The rate of lung contusion seen in almost $1 / 3$ of trauma patients has been reported in a wide range of 11 to $30 \%$ in different sources, and lung contusion is known to have a major impact on mortality $[4-6,20]$. In this study, this rate was found to be $19.5 \%$ in accordance with the literature. Many cases with thoracic trauma can be treated without requiring surgical treatment. The rate of injury requiring thoracotomy in thoracic trauma has been reported between 3-14\% $[5,21,22]$. In this study, the number of patients who underwent thoracotomy was 2 . This rate is quite low compared to the literature. The proportion of patients who were applied tube was $45 \%$. Tube thoracostomy rate appears to be higher than $29 \%$ reported in the literature [23].

Like the morbidity of patients with thorax trauma, the length of hospital stay can vary in a wide range. No publication was found in the literature regarding the length of hospital stay. There are many factors that affect the length of hospital stay, especially in patients with additional injury. Besides the patients factors, many factors such as injury type, complication, intensive care or being treated in the service may affect this period. In this study, a negative weak relationship was found with age and oxygen saturation. In other words, as the oxygen saturation decreases, the length of hospital stay increases. This means that the patient with more severe thoracic trauma stays longer, which is not unreasonable. But it does not seem possible to say the same thing for age. As a result of the age of hospitalization decreases with increasing age, elderly patients should not mean as if they recover more quickly. This situation may not be interpreted correctly due to the limited number of patients, and the earlier death of older patients may have caused a shorter hospital stay.

In this study, the mortality rate was $5.3 \%$. This rate has been reported in the literature as between $9 \%$ and $20 \%$ [24]. The low mortality rate, which is the result of this study, may be due to inclusion criteria. Already, high mortality conditions such as major vascular injury in thoracic trauma are lost at the scene in the first minutes. Since the patients with absolute fatal trauma outside the thorax and those who died in the emergency service were also excluded from the study, the mortality among the remaining patients may have been low compared to the literature. The hypothesis of this study that 'the use of anticoagulants may increase mortality by making it difficult to stop bleeding or stop spontaneously' is not supported by this study results. This situation may vary depending on the patients International Normalized Ratio (INR) value at the time. In addition, the fact that only one patient uses anticoagulant drugs among the patients who died makes it difficult to say whether there is a relationship between mortality or not.

\section{CONCLUSION}

As a result, in this study, thoracic trauma occurs mostly in men and due to falls and motor vehicle accidents 
and the majority of injuries due to thoracic trauma can heal without follow-up or tube thoracostomy.

\section{REFERENCES}

1. The Science Base for Prevention of Injury and Violence. CDC Web site Available at https://www.cdc.gov/cdcgrandrounds/archives/2012/ january2012.htm.Accessed; 10: Dec.

2. Lecky F, Bouamra 0, Woodford M, et al. Epidemiology of Polytrauma. Damage Control Management in the Polytrauma Patient. 2010: 13-24, doi: 10.1007/978-0-387-89508-6_2.

3. Soysal 0. Blunt torax trauma. In: Yüksel M, Kalaycı G, Yüksel M, editors. Thorax surgery. 1st ed. Istanbul: Bilmedya Group; 2001. p. 447-64. [In Turkish].

4. Eren MN, Balcı AE. Torak travmaları. In: Ökten I, Güngör A, editörler. Göğü cerrahii. Ankara: Sim Matbaacılık; 2003. s. : 661-88.

5. Tekinbaş C, Eroğlu A, Kürkçüoğlu ic, et al. Toraks travmaları: 592 olgunun analizi. Ulus Travma Acil Cerrahi Derg. 2003; 9: 275-80.

6. Leblebici HI, Kaya Y, Koçak AH. Göğüs travmalı 302 olgunun analizi. Türk Göğüs Kalp Damar Cer Derg. 2005; 13: 392-6.

7. Oikonomou A, Prassopoulos P. CT imaging of blunt chest trauma. Insights Imaging. 2011; 2(3): 281-295, doi: 10.1007/s13244-0110072-9, indexed in Pubmed: 22347953.

8. Liman ST, Kuzucu A, Tastepe Al, et al. Chest injury due to blunt trauma. Eur J Cardiothorac Surg. 2003; 23(3): 374-378, doi: 10.1016/s10107940(02)00813-8, indexed in Pubmed: 12614809.

9. Dehghan N, de Mestral C, McKee MD, et al. Flail chest injuries: a review of outcomes and treatment practices from the National Trauma Data Bank. J Trauma Acute Care Surg. 2014; 76(2): 462-468, doi: 10.1097/ TA.0000000000000086, indexed in Pubmed: 24458051.

10. de Jong MB, Kokke MC, Hietbrink F, et al. Surgical Management of Rib Fractures: Strategies and Literature Review. Scand J Surg. 2014; 103(2): 120-125, doi: 10.1177/1457496914531928, indexed in Pubmed: 24782038.

11. Sirmali $M$, Türüt $H$, Topçu $S$, et al. A comprehensive analysis of traumatic rib fractures: morbidity, mortality and management. Eur J Cardiothorac Surg. 2003; 24(1): 133-138, doi: 10.1016/s10107940(03)00256-2, indexed in Pubmed: 12853057.
12. Segers $P$, Van Schil $P$, Jorens $P$, et al. Thoracic trauma: an analysis of 187 patients. Acta Chir Belg. 2001; 101(6): 277-282, indexed in Pubmed: 11868503.

13. Mayberry JC, Kroeker AD, Ham LB, et al. Long-term morbidity, pain, and disability after repair of severe chest wall injuries. Am Surg. 2009; 75(5): 389-394, indexed in Pubmed: 19445289.

14. Mayberry JC, Ham LB, Schipper PH, et al. Surveyed opinion of American trauma, orthopedic, and thoracic surgeons on rib and sternal fracture repair. J Trauma. 2009; 66(3): 875-879, doi: 10.1097/ TA.0b013e318190c3d3, indexed in Pubmed: 19276767.

15. Heyes FL, Vincent R. Sternal fracture: what investigations are indicated? Injury. 1993; 24(2): 113-115, doi: 10.1016/0020-1383(93)90201$\mathrm{g}$, indexed in Pubmed: 8505116.

16. Thompson DA, Flynn TC, Miller PW, et al. The significance of scapular fractures. J Trauma. 1985; 25(10): 974-977, doi: 10.1097/00005373198510000-00008, indexed in Pubmed: 4046086.

17. ABDOMINAL TRAUMA. ACCIDENT AND EMERGENCY MEDICINE. : 4-6, doi: 10.4324/9780203450352_abdominal_trauma.

18. Emircan $S$, Ozguc $H$, Aydin $S$, et al. Factors affecting mortality in patients with thorax trauma. Turkish Journal of Trauma and Emergency Surgery. 2011; 17(4): 329-333, doi: 10.5505/tites.2011.76158.

19. İmamoğlu OU, Öncel M, Erginel T, et al. ve ark. Toraks travmalarında yaklaşım: 110 olgunun değerlendirilmesi. Türk Göğüs Kalp Damar Cer Derg. 1999; 7: 450-3.

20. Er M, Işık AF, Kurnaz M, et al. Göğüs travmalı 424 olgunun sonuçları. Ulus Travma Acil Cerrahi Derg. 2003; 9: 267-74.

21. Başoğlu $A$, Akdağ $A 0$, Çelik $B$, et al. Göğüs travmalar): 521 olgunun değerlendirilmesi. Ulus Travma Acil Cerrahi Derg. 2004; 10: 42-6.

22. Çağıııı U, Uç H, Çalkavur T, et al. ve ark. Toraks travmaları: 6 yıllık deneyimlerimiz. Ulus Travma Acil Cerrahi Derg. 1998; 4: 248-52.

23. Zakharia AT. Thoracic battle injuries in the Lebanon War: review of the early operative approach in 1,992 patients. Ann Thorac Surg. 1985; 40(3): 209-213, doi: 10.1016/s0003-4975(10)60029-x, indexed in Pubmed: 4037912.

24. Chamion HR, Sarıbeyoğlu K. Trauma score. In: Ertekin C, Tavioğlu K, Kurdoglu M, Guloglu R, editors. Trauma 1st ed istanbul: i̇stanbul Medikal 2005 p 78-82. (In Turkish). 